\title{
A Risk-Averse Newsvendor Model under Stochastic Market Price
}

\author{
Huirong Zhang $\mathbb{D}^{1}{ }^{1}$ Zhenyu Zhang $\mathbb{D}^{2}{ }^{2}$ and Jiaping Zhang $\mathbb{D}^{3}$ \\ ${ }^{1}$ School of Labor Relationship, Shandong Management University, Jinan 250357, China \\ ${ }^{2}$ School of Automation, Nanjing University of Science and Technology, Nanjing 210094, China \\ ${ }^{3}$ School of Public Administration, East China Normal University, Shanghai 200062, China \\ Correspondence should be addressed to Zhenyu Zhang; zhangzhenyu7@foxmail.com
}

Received 27 May 2021; Revised 4 August 2021; Accepted 18 August 2021; Published 1 September 2021

Academic Editor: Haoran Zhang

Copyright (C) 2021 Huirong Zhang et al. This is an open access article distributed under the Creative Commons Attribution License, which permits unrestricted use, distribution, and reproduction in any medium, provided the original work is properly cited.

\begin{abstract}
The optimal inventory control is closely related to an enterprise's operational efficiency, survival, and development. Market price uncertainty is introduced into the newsvendor model and the uncertainty's impact on the firm's optimal stocking quantity is discussed. The results show that the impact of stochastic market price on the optimal stocking quantity under a given condition mainly depends on the magnitude of inventory cost. When the inventory cost is low, the market price's uncertainty leads the firm to increase the stocking quantity. In contrast, when the inventory cost is high, market price uncertainty leads the firm to decrease inventory. Besides, the risk-averse behaviour leads the firm to reduce its stocking quantity.
\end{abstract}

\section{Introduction}

The classical newsboy problem is widely used in manufacturing, retail, and management industries, but it does not fully reflect and solve the more complex problems of real life. There is a great deal of uncertainty in the marketplace, leading to uncertainty in the entire ordering and selling process, such as the supplier's production capacity, the rate of conformity, the availability of supply, the accessibility of the transport network, and the demand for the product in the market. These uncertainties affect the entire decision-making process in random variables, making market trade risky. Market participants have their attitudes towards risk, including risk preferences, risk neutrality, and risk aversion. Market participants are risk-neutral by default when risk factors are not taken into account. In reality, investors are often risk-averse. The issue of risk aversion is more reflective of the subjective intentions of decisionmakers in real-life situations. Risk aversion for decisionmakers to increase returns is also the main objective of the classical newsboy model.

The newsvendor model is fundamental in supply chain management [1-3]. The traditional newsvendor model solves the problem of the optimal stocking quantity of a firm under a single cycle of a single variety of products [4]. The optimal stocking quantity relies on three factors: fixed inventory cost, market price, and market demand inscribed by nonnegative random variables. There are two main assumptions of existing studies on market prices: one is that prices are exogenous and fixed [5-8]; the other is that prices are endogenous and determined by firms [9-11]. However, the actual situation is that market prices are stochastic [12], and firms do not know what the future sales price and the market price will be in the early ordering stage. As modern firms gradually adopt long-term order planning or long-term inventory management, the inability to know the exact sales price at the ordering stage becomes more obvious. The impact of stochastic market prices on inventory management becomes more prominent [13].

Therefore, the optimal stocking quantity at stochastic market prices is analyzed and the effect of price stochasticity on the optimal inventory is investigated. The contributions of the developed methods are as follows. Firstly, some newsvendor models under stochastic market prices are developed. The optimal inventory decisions under stochastic market prices are analyzed, and the influence of the randomness on the optimal inventory is discussed. Secondly, a 
risk-averse newsvendor model under stochastic market price is proposed to prove that the risk aversion behaviour will reduce the optimal inventory.

The rest of this paper is organized as follows and is shown in Figure 1. Some related works of newsvendor models are introduced in Section 2. Section 3 provides some problem definitions and model reformulation and solution on newsvendor model under stochastic market price and the risk-averse newsvendor model under stochastic market price. Finally, some conclusions are given in Section 4.

\section{Literature Reviews}

The newsvendor model is closely related to the market prices. The existing researches on market price contain two assumptions. One is that market prices are exogenous and fixed, and the other is that market prices are endogenous and determined by firms.

Some researches on newsvendor problems assumed that market prices are endogenous and decided by firms. Sandmo [14] studied the optimal output at uncertain prices and found that the optimal output at uncertain prices is smaller than the optimal output at fixed prices. In addition, Sandmo's introduction of uncertainty into market prices changes the traditional model. For example, the existence of optimal output when market prices are fixed requires that marginal production costs are increasing, while the existence of optimal output when market prices are stochastic does not require this condition. Sandmo found that firms had a positive output level only when the expectation of stochastic market prices was greater than average production costs, and the result was consistent with their findings. Pindyck [15] found that the rate of resource production is affected by the stochasticity of future exogenous prices. Pindyck pointed out that future resource prices are stochastic in many cases, and this stochasticity can change production behaviour. Batra and Ullah [16] showed that price uncertainty could cause firms to reduce inputs in many cases. Hartman [17] finds that Batra and Ullah's results rely on an important assumption that the input levels of all factors are determined simultaneously. Price uncertainty can also lead to hedging [18] and the existence of futures markets [19]. Konstantaras et al. [20] investigated a single-level inventory system with deterministic demand and unreliable supply, exhibiting endogenous disruptions in supply, and analyzed the property of the optimal decision variables and costs associated with the quality of the supply process. Green et al. [21] applied the newsboy model to the nurse scheduling problem and analyzed a single-cycle nurse staffing model in the face of determined nurse staffing levels and endogenous service capacity uncertainty to effectively address the lack of service levels due to nurse absenteeism. Ekin et al. [22] proposed a simulation-based approach to solving the newsboy problem and the stock problem for stochastic optimisation problems with resource and endogenous uncertainty. Ekin et al. [23] developed a computationally efficient simulation method for discrete stochastic optimisation problems for the endogenous uncertainty supplier problem. Kirshner and Shao [24] combined prospect theory to develop a model of supplier ordering decisions that consider overconfidence and optimism. The results showed that greater optimism, overconfidence, and regret typically lead to lower profitability and increased inventory. Mitra and Chatterjee [25] developed a newsvendor model considering the single-phase single-item and single-cycle under stochastic seasonal demand to determine the optimal order quantity and expected profit. The results showed that deviations between the actual values and model solutions are also sensitive to the salvage prices and contribution margin.

Some other researchers think that the market prices are exogenous and fixed. Pindyck [15] argued that the market price of oil is exogenous because OPEC determines it. Like Sandmo [14], Batra and Ullah [16] explored the optimal inputs and outputs under market price uncertainty. In Batra and Ullah's model, the market price was exogenously determined in a probabilistic sense. The firm was not strong enough to influence the prior distribution of sales prices. In contrast to the assumption of endogenous market prices, studies in this area usually assume that the relationship between market prices and demand was portrayed by an implicit function, which is unknown before the selling season but has a known prior probability distribution [26]. Wei et al. [27] proposed a newsvendor ordering decision model based on industry benchmark and profit minimum requirement and investigated the influence of exogenous reference points on ordering quantity. The results showed that the reference profit and the cost of shortage significantly influence the supply chain behaviour. Wang and Johnson [28] established the tri-reference point (TRP) theory to divide the risk status into success, gain, loss, and failure. Wang and Webster [7] assumed that the market prices were fixed and constructed the manager's decision-making behaviour model. The optimal order quantity of risk-averse newsboys may increase the wholesale price and decrease the retail price. Long and Nasiry [29] regarded the existing status as the reference point and developed a prospect theory-based newsvendor model. Wu et al. [30] investigated a loss-averse competitive news supplier problem with the anchor. They found that the order quantity of newsboys decreased with the degree of loss aversion and anchor value. Zhou et al. [31] constructed a multiperiod supply chain network equilibrium model considering retailer's dynamic risk aversion behaviour. Retailer's loss aversion behaviour increased retailer's profit and increased the supply chain network's total profit. Lee et al. [32] examined the impact of newsboys' loss aversion behaviour on their ordering decisions and proposed a loss aversion newsboy model that takes into account stochastic demand. Garvey and Carnovale [33] proposed a single-cycle newsboy model considering the supply chain network structure, which mainly studied the optimal inventory and production policy. Local exogenous risk is more important than nonlocal exogenous risk. Vipin and Amit [34] developed a newsvendor model considering risk-aversion under risk-neutral assumption. The order quantity decreased when the selling price increased, and the selling price was insensitive to the order quantity.

However, the existing researches have ignored the stochastic market prices and the firm managers' risk-averse attitudes. Therefore, the optimal stocking quantity at stochastic 


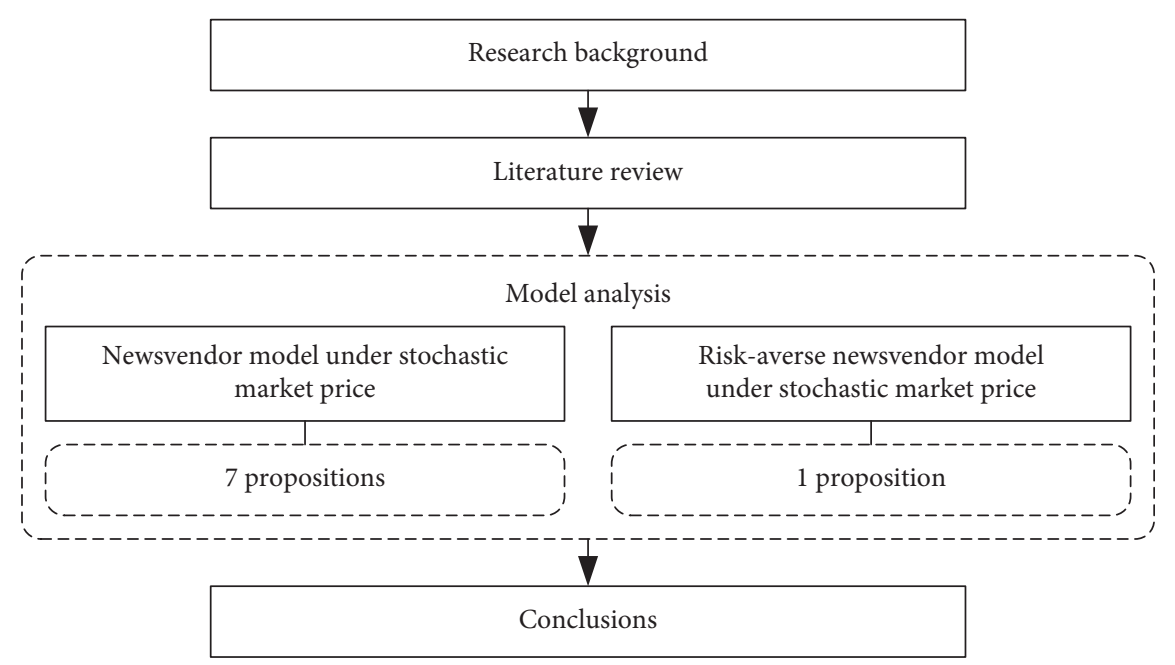

Figure 1: The flowchart of the developed newsvendor model.

market prices is analyzed and the effect of price stochasticity on the optimal inventory is investigated in this paper.

\section{Model Analysis}

In this section, we introduce the newsvendor model analysis under stochastic market price, including problem definition, initial model formulation, and model reformulation and solution, as shown in Figure 2.

\subsection{Problem Definition and Initial Model Formulation.} Consider a retailer in a market that needs to determine the stocking quantity $q$ before the selling season. The information known at the time of order includes the unit inventory cost of product $c$ and the price in the selling season is inscribed by a nonnegative random variable $P$ defined on $[0, \bar{p}]$, where $f(p)$ is the probability density function of $P$, $F(p)$ is the probability distribution function, and $\mu$ is the mean value of market price. The demand function may also be stochastic when the realized price in the selling season is $p$.

Assume that the market demand is

$$
D(p)=D_{1}(p)+D_{2}(p) X,
$$

where $X$ is a finite nonnegative random variable with a probability density function $g(x)$ and a probability distribution function $G(x)[10]$. Assume that $\left(\mathrm{d} D_{1}(p) / \mathrm{d} p\right)<0$ or $D_{1}(p)$ is a constant, $\left(\mathrm{d} D_{2}(p) / \mathrm{d} p\right)<0$ or $D_{2}(p)$ is a constant, $D_{1}(\bar{p})=0$, and $D_{2}(\bar{p})=0$. That is, an increase in market price always causes a decrease in market demand, and when $D_{1}(p)$ is constant at 0 , the market demand is multiplicative; when $D_{2}(p)$ is constant at 1 , the market demand is additive. These two forms of market demand are widely used. In addition, assume that $G(\cdot)$ is a strictly increasing function.

The firm's revenue is

$$
\pi(q)=p \min (D(p), q)-c q .
$$

The firm's objective is to maximize its expected returns, and the expected return is

$$
E(\pi(q))=E[p \min (D(q), q)]-c q .
$$

Before further analysis, the optimal stocking quantity at a determined price as a reference is given. That is, if the firm is informed that the price for the selling season is a deterministic value $\mu$, then the optimal stocking quantity is

$$
q_{\mu}=D_{1}(\mu)+D_{2}(\mu) G^{-1}\left(\frac{\mu-c}{\mu}\right) \text {, }
$$

where $G^{-1}(\cdot)$ is the inverse function of $G(\cdot)$.

Above all, the summary of notations is provided in Table 1.

\subsection{Model Reformulation and Solution}

3.2.1. Newsvendor Model under Stochastic Market Price. Next, the optimal stocking quantity at stochastic prices is analyzed and the effect of this stochasticity on the size of the optimal stocking quantity is explored.

All possible scenarios of the demand form are listed in Table 1 . The optimal stocking quantity can be calculated from the traditional paperboy model for the mundane cases in Table 2, that is, when $D_{1}(p)$ and $D_{2}(p)$ all are degenerate. Next, the optimal stocking quantity in the general case is introduced.

(1) In the Case of $D_{1}(p) \neq$ Constant, $D_{2}(p)=0$. Firstly, the model of the case $D_{1}(p) \neq$ constant, $D_{2}(p)=0$ is analyzed; that is, when the market price is given, the market demand is fixed.

Then equation (3) can be calculated as

$$
\begin{aligned}
E(\pi(q)) & =E[p \min (D(q), q)]-c q \\
& =\int_{0}^{D_{1}^{-1}(q)} p q f(q) \mathrm{d} p+\int_{D_{1}^{-1}(q)}^{+\infty} p D_{1}(p) f(p) \mathrm{d} p-c q .
\end{aligned}
$$

By deriving equation (5), we have 


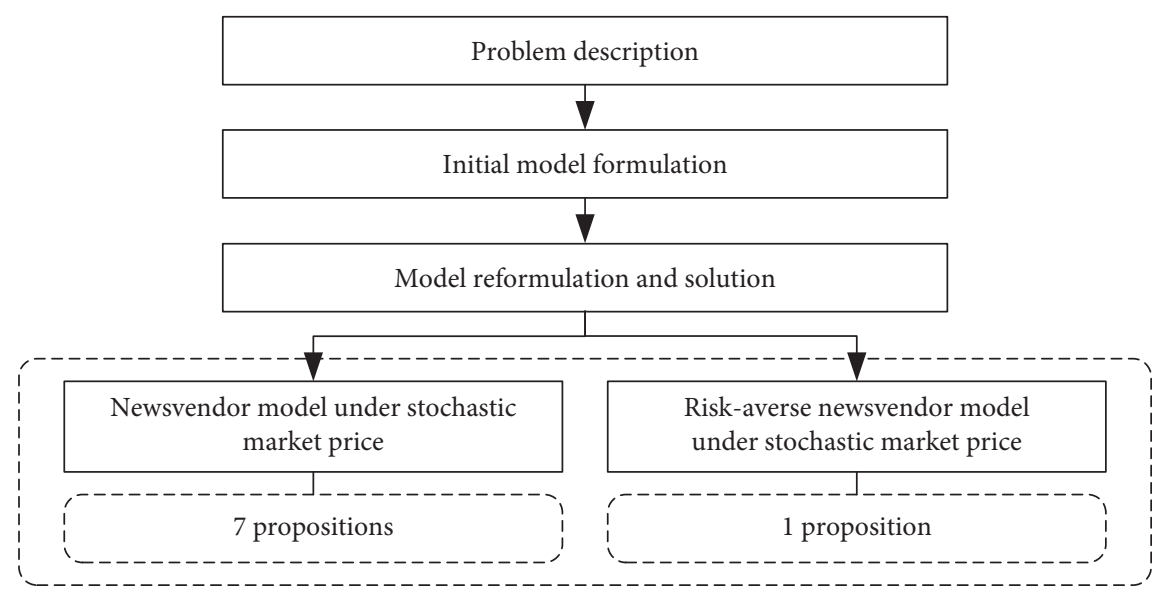

FIGURE 2: The newsvendor model under stochastic market price.

TABLE 1: Summary of notations.

\begin{tabular}{lc}
\hline Notation & Description \\
\hline$p$ & Market price \\
$q$ & Stocking (order) quantity \\
$c$ & Unit inventory cost \\
$\mu$ & The mean value of market price \\
$f(p)$ & The probability density function \\
$F(p)$ & The probability distribution function \\
$D(p)$ & Market demand \\
$\pi(p)$ & The firm's revenue \\
$q_{\mu}$ & The optimal stocking quantity \\
\hline
\end{tabular}

TABle 2: All possible scenarios of $D_{1}(p)$ and $D_{2}(p)$.

\begin{tabular}{lccr}
\hline$D_{1}(p)$ & & $D_{2}(p)$ & Cot constant \\
\hline 0 & 0 & Trivial & General \\
Constant $(\neq 0)$ & Trivial & Trivial & General \\
Not constant & Trivial & General & General \\
\hline
\end{tabular}

$$
\begin{aligned}
\frac{\mathrm{d} E(\pi)}{\mathrm{d} q} & =\int_{0}^{D_{1}^{-1}(q)} p f(p) \mathrm{d} p-c, \\
\frac{\mathrm{d}^{2} E(\pi)}{\mathrm{d} q^{2}} & =D_{1}^{-1}(q)\left(D_{1}^{-1}\right)^{\prime}(q) f\left(D_{1}^{-1}(q)\right) .
\end{aligned}
$$

Proposition 1. If $D_{1}(p) \neq$ constant, $D_{2}(p)=0$, then when $0<c<\mu$, the optimal stocking quantity $q^{*}$ satisfies $\int_{0}^{D_{1}^{-1}\left(q^{*}\right)} p f$ $(p) d p=c$; when $c \geq \mu$, the optimal stocking quantity is $q^{*}=0$.

Proposition 2. There exists a unique $\bar{c}, 0<\bar{c}<\mu$, such that when $c<\bar{c}, q^{*}>q_{\mu}$; when $\bar{c}<c<\mu, 0<q^{*}<q_{\mu}$; when $c \geq \mu$, $q^{*}=q_{\mu}=0$.

From Proposition 2, when the inventory cost is less than a certain critical value, the optimal stocking quantity at the stochastic market price is greater than the optimal stocking quantity at the deterministic market price, that is, the uncertainty of the market price will lead the firm to order more. When the inventory cost is greater than or equal to a certain critical value, the optimal stocking quantity at the stochastic market price is less than or equal to the optimal stocking quantity at the deterministic market price; that is, the uncertainty of the market price will lead the firm to order less. The following example can prove the above conclusions.

Example 1. Assuming that the market price $P$ follows a uniform distribution on $[0,1], D_{1}(p)=1-p$, and $D_{2}(p)$ is constant at 0 .

According to Proposition $1, q^{*}=D_{1}(\sqrt{2 c})$. When $D_{1}(p)=1-p, q^{*}=1-\sqrt{2 c}$. The optimal stocking quantity under the fixed market price $p=\mu=(1 / 2)$ is $q_{\mu}=(1 / 2)$. After calculation, the optimal stocking quantity under fixed market price is calculated as follows:

(1) When $c<(1 / 8), q^{*}>q_{\mu}$

(2) When $c=(1 / 8), q^{*}=q_{\mu}>0$

(3) When $(1 / 8)<c<(1 / 2), q^{*}<q_{\mu}$

(4) When $c \geq(1 / 2), q^{*}=q_{\mu}=0$ 


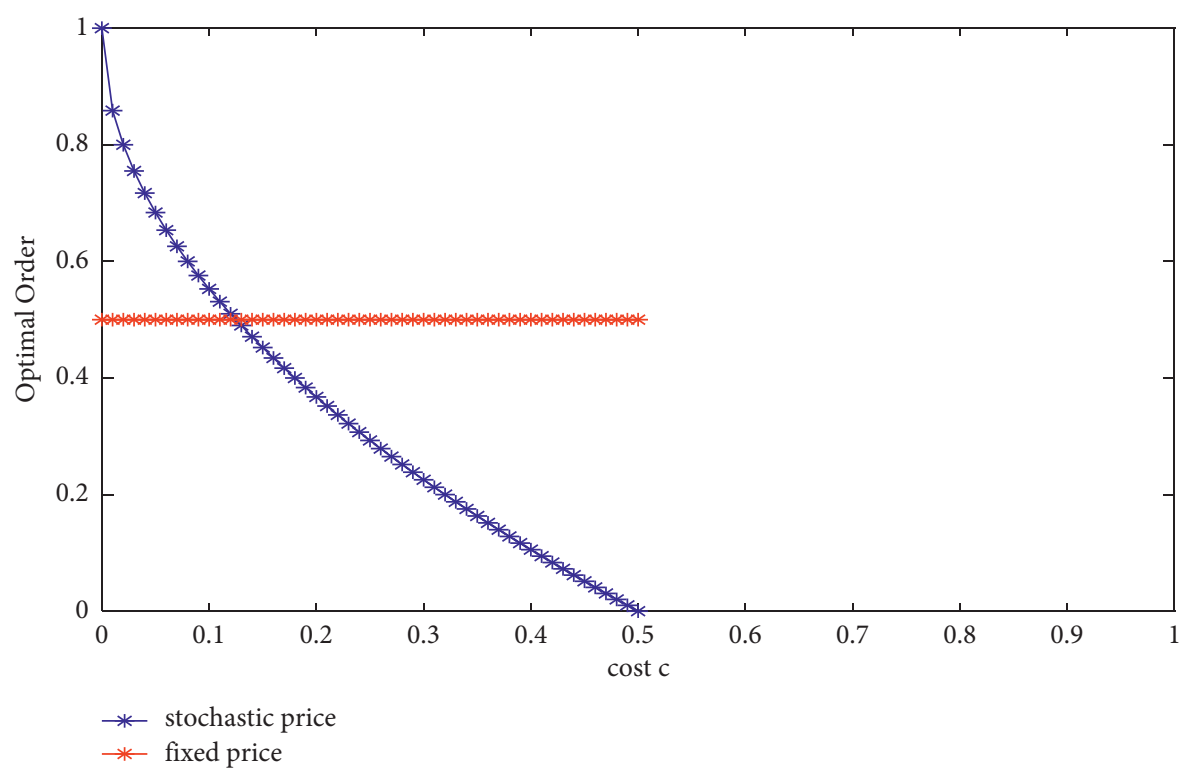

Figure 3: The optimal order under the stochastic price and fixed price.

The result of Example 1 is shown in Figure 3.

(2) In the Case of $D_{2}(p)$ Being Not Constant at 0. Next, the other general cases are studied; that is, when $D_{2}(p)$ is not constant at 0 , the optimal stocking quantity of the firm at the stochastic market price is investigated. In this case, the firm's expected profit function is

$$
\begin{aligned}
E(\pi) & =\int_{0}^{+\infty} p f(p)\left[\int_{0}^{\left(\left(q-D_{1}(p)\right) / D_{2}(p)\right)}\left(D_{1}(p)+D_{2}(p) x\right) g(x) \mathrm{d} x+\int_{\left(\left(q-D_{1}(p)\right) / D_{2}(p)\right)}^{+\infty} q g(x) \mathrm{d} x\right] \mathrm{d} p-c q \\
& =E\left[p \int_{0}^{\left(\left(q-D_{1}(p)\right) / D_{2}(p)\right)}\left(D_{1}(p)+D_{2}(p) x\right) g(x) \mathrm{d} x\right]+E\left[p \int_{\left(\left(q-D_{1}(p)\right) / D_{2}(p)\right)}^{+\infty} q g(x) \mathrm{d} x\right]-c q .
\end{aligned}
$$
follows:

It can be obtained by the derivation of equation (7) as

$$
\begin{aligned}
& \frac{\partial E(\pi)}{\partial q}=E\left[p\left(1-G\left(\frac{q-D_{1}(p)}{D_{2}(p)}\right)\right)\right]-c, \\
& \frac{\partial^{2} E(\pi)}{\partial q^{2}}=E\left[\frac{p}{D_{2}(p)} G^{\prime}\left(\frac{q-D_{1}(p)}{D_{2}(p)}\right)\right] .
\end{aligned}
$$

Proposition 3. If $D_{2}(p)$ is not constant, when $0<c<\mu$, the optimal stocking quantity $q^{*}$ satisfies $E\left[p\left(1-G\left(\left(q^{*}-D_{1}\right.\right.\right.\right.$ $\left.\left.\left.(p)) / D_{2}(p)\right)\right)\right]=c$; when $c \geq \mu, q^{*}=0$.

Next, the impact of market price randomness on the optimal stocking quantity is discussed.

Proposition 4. If $D_{1}(p)$ is not constant and $D_{2}(p)$ is not constant at 0 , then there exists $\bar{c} \in(0, \mu)$ such that $q^{*}(\bar{c})=q_{\mu}(\mu)$.

Proposition 4 shows that the optimal stocking quantity at a random market price can be equal to the inventory cost at a fixed price when the inventory cost is located at $(0, \mu)$. Further, when $X$ obeys the uniform distribution, the following proposition can be put forward.
Proposition 5. If $D_{1}(p)$ is not constant, $D_{2}(p)$ is not constant at 0 , and $X$ obeys uniform distribution on $[0,1]$, then there exists $\bar{c} \in(0,1)$ such that when $0<c<\bar{c}, q^{*}>q_{\mu}$; when $\bar{c} \leq c<\mu, q^{*} \leq q_{\mu}$; when $c \geq \mu, q^{*}=q_{\mu}=0$.

Proposition 5 shows that when the uncertainty of demand follows a uniform distribution, a critical value of inventory cost makes the randomness of market price make firms order more when the inventory cost is less than the critical value. When the inventory cost is greater than the critical value, the randomness of market price makes firms order less.

Proposition 6. When $D_{1}(p)$ is constant at $0, D_{2}(p)$ is not constant at 0 ; if $\left(p / D_{2}(p)\right)$ is a convex function, then there exists $\bar{c} \in(0, \mu)$ such that when $c<\bar{c}, q^{*}<q_{\mu}$; when $\bar{c} \leq c<\mu$, $q^{*} \leq q_{\mu} ;$ when $c \geq \mu, q^{*}=q_{\mu}=0$.

Proposition 6 gives a sufficient condition for the existence of a critical value.

Proposition 7. When $D_{1}(p)$ is constant at $0, D_{2}(p)$ is not constant at 0 ; if $\left(p / D_{2}(p)\right)$ is a concave function, for $c \in(0, \mu)$, then $q^{*}>q_{\mu}$. 
Proposition 7 shows that when $\left(p / D_{2}(p)\right)$ is a concave function, the optimal stocking quantity at a stochastic market price is always greater than the optimal stocking quantity at a deterministic market price. In this case, the firm always tends to order more.

\subsubsection{The Risk-Averse Newsvendor Model under Stochastic} Market Price. In this section, how the optimal stocking quantity is affected if the firm is risk-averse is investigated. Assuming that $w_{0}$ is the firm's initial wealth, $u(w)$ is the firm's utility function, $w$ is the firm's total wealth, and $u(w)$ satisfies $u^{\prime}(w)>0$ and $u^{\prime \prime}(w)<0$. The first-order derivative is greater than 0 , indicating that the firm's utility increases with increasing wealth. The second-order derivative is less than 0 , indicating that the firm's utility increases at a decreasing rate with increasing wealth, meaning that the firm is risk-averse. When the firm's order quantity is $q$, the firm's expected utility function is

$$
E\left(\pi_{a}\right)=E\left[u\left(w_{0}+p \min \left(q, D_{1}(p)+D_{2}(p) X\right)\right)-c q\right] .
$$

Assume that $q_{a}$ is the optimal stocking quantity of the firm in the risk-averse case; then we have the following.

Proposition 8. If the firm is risk-averse, then $q_{a}<q^{*}$.

Proposition 8 shows that uncertainty in market prices always makes firms order less if they are risk-averse. Eeckhoudt et al. [35] proposed that firms tend to order less when market prices are fixed, and market demand is stochastic. The result obtained by Proposition 8 also confirms the conclusion. When market prices have some randomness, firms order less.

\section{Conclusions}

In modern markets, the market prices of products are generally characterized by uncertainty and randomness. Since the production of a product requires a series of complex processes, firms usually have to prepare their inventories long before the sales season and then need to consider the effect of future price uncertainty in the optimal inventory decision.

In this paper, the stochasticity of market prices is introduced into the classical newsvendor model to discuss the optimal stocking quantity of the firm. The results show that stochastic market prices lead to higher or lower optimal stocking quantities depending on the magnitude of inventory costs compared to the optimal stocking quantity at a fixed market price. Specifically, when the inventory cost is below a certain threshold, firms tend to prepare more inventory. Firms tend to order more when the inventory cost is above a certain threshold but less than the expected market price. When the inventory cost is above the expected market price, firms' optimal stocking quantity is zero. In addition, this paper finds that an increase in inventory cost always reduces the optimal stocking quantity, which is intuitive and realistic. Finally, this paper introduces risk-averse behaviour into the model and demonstrates that risk-averse behaviour reduces the optimal stocking quantity.

However, there are some limitations in the developed newsvendor model. Firstly, supply chain management involves uncertain, robust, and fuzzy information [36-40]. Secondly, stochastic market price and decision-makers' attitudes towards risk are not defined in supply chain management [41]. Therefore, the newsvendor model by handling the fuzzy and uncertain information and decision-makers' risk attitudes and preferences will be improved in the future. Thirdly, the developed newsvendor model will be introduced to other applications, such as renewable energy supply chain management [42].

\section{Appendix}

\section{Proof of Proposition 1}

Proof. According to the first-order and second-order conditions satisfied by the optimal stocking quantity, it can be obtained directly.

In addition, when $0<c<\mu$, according to the implicit function theorem, we have

$$
\frac{\mathrm{d} q^{*}}{\mathrm{~d} c}=\frac{1}{D_{1}^{-1}\left(q^{*}\right)\left(D_{1}^{-1}\right)^{\prime}(q) f\left(D_{1}^{-1}\left(q^{*}\right)\right)}<0 .
$$

It shows that the optimal stocking quantity decreases as $c$ increases.

\section{Proof of Proposition 2}

Proof. Note that the optimal order when the price is deterministic is

$$
q_{\mu}= \begin{cases}D_{1}(\mu), & c<\mu \\ 0, & c \geq \mu\end{cases}
$$

When $c=0, q^{*}=D_{1}(0)$, and $D_{1}(0)>D_{1}(\mu)$, then $q^{*}>q_{\mu}$; when $c \geq \mu$, the optimal stocking quantities are all 0 . Combining the continuity and decreasing nature of $q^{*}(c)$, the proposition can be proven.

\section{Proof of Proposition 3}

Proof. According to the first-order and second-order conditions of the optimal stocking quantity, the proposition can be proven.

In addition, according to the implicit function theorem, we have

$$
\frac{\mathrm{d} q^{*}}{\mathrm{~d} c}=-\frac{\left(\partial^{2} E(\pi) / \partial q \partial c\right)}{\left(\partial^{2} E(\pi) / \partial q^{2}\right)}=-\frac{1}{E\left[\left(p / D_{2}(p)\right) G^{\prime}\left(\left(q^{*}-D_{1}(p)\right) / D_{2}(p)\right)\right]}<0
$$


The above formula shows that when $D_{2}(p)$ is not constant at 0 , the optimal stocking quantity $q^{*}$ decreases with the increase of inventory cost.

\section{Proof of Proposition 4}

Proof

$$
\begin{aligned}
& \lim _{c \longrightarrow 0}\left(q^{*}-q_{\mu}\right)=D_{1}(0)-D_{1}(\mu)+\left(D_{2}(0)-D_{2}(\mu)\right) \sup \{X\}>0, \\
& \lim _{c \longrightarrow \mu}\left(q^{*}-q_{\mu}\right)=-D_{1}(\mu)<0 .
\end{aligned}
$$

Then the proposition can be proven.

\section{Proof of Proposition 5}

Proof. For $x \in[0,1], g(x)=1$. Then $\left(\mathrm{d} q^{*} / \mathrm{d} c\right)$ decreases as $c$ increases. $q^{*}$ is a concave function of $c$ on $(0, \mu)$. In addition, it is easy to obtain that $q_{\mu}$ is a linear function on $c$, where the intersection point is unique. Proposition 5 is proved.

\section{Proof of Proposition 6}

Proof. Firstly, it is easy to prove that there is a unique intersection point between $q^{*}$ and $q_{\mu}$ on $(0, \mu)$ if and only if $E\left(p / D_{2}(p)\right)>\left(\mu / D_{2}(\mu)\right)$; there is no intersection point between $q^{*}$ and $q_{\mu}$ on $(0, \mu)$ if and only if $E\left(p / D_{2}(p)\right)<\left(\mu / D_{2}(\mu)\right)$.
Similarly, $q^{*}$ is a concave function of $c$. In addition, $q_{\mu}=D_{2}(\mu)((\mu-c) / \mu)$; it means that $q_{\mu}$ is a linear function of $c$. Thus, there are at most two intersections between $q^{*}$ and $q_{\mu}$.

In addition, $\lim _{q^{*}} \longrightarrow 0\left(\mathrm{~d} q^{*} / \mathrm{d} c\right)=-\left(1 / E\left[p / D_{2}(p)\right]\right)$, and $\left(\mathrm{d} q_{\mu} / \mathrm{d} c\right)=-\left(D_{2}(\mu) / \mu\right) \cdot q^{*}$ is a concave function of $c$ if and only if $E\left[p / D_{2}(p)\right]>\left(\mu / D_{2}(\mu)\right)$. There exist two intersections between $q^{*}$ and $q_{\mu}$. Therefore, there is a unique intersection on $(0, \mu)$. Similarly, there is no intersection on $(0, \mu)$ if and only if $E\left[p / D_{2}(p)\right]<\left(\mu / D_{2}(\mu)\right)$. Proposition 6 can be proven.

\section{Proof of Proposition 8}

Proof. When $D_{2}(p)$ is constant at 0 , we have

$$
\begin{aligned}
E\left(\pi_{a}(q)\right) & =E\left[u\left(w_{0}+p \min \left(q, D_{1}(p)\right)\right)-c q\right] \\
& =\int_{0}^{D_{1}^{-1}(q)} u\left(w_{0}+p q-c q\right) f(p) \mathrm{d} p+\int_{D_{1}^{-1}(q)}^{+\infty} u\left(w_{0}+p D_{1}(p)-c q\right) f(p) \mathrm{d} p .
\end{aligned}
$$

Then

$$
\begin{aligned}
\frac{\mathrm{d} E\left(\pi_{a}\right)}{\mathrm{d} q}= & \int_{0}^{D_{1}^{-1}(q)} u^{\prime}\left(w_{0}+p q-c q\right)(p-c) f(p) \mathrm{d} p+\int_{D_{1}^{-1}(q)}^{+\infty} u^{\prime}\left(w_{0}+p D_{1}(p)-c q\right)(-c) f(p) \mathrm{d} p \\
& <\int_{0}^{D_{1}^{-1}(q)} u^{\prime}\left(w_{0}+p q-c q\right)(p-c) f(p) \mathrm{d} p+\int_{D_{1}^{-1}(q)}^{+\infty} u^{\prime}\left(w_{0}+p q-c q\right)(-c) f(p) \mathrm{d} p \\
= & \int_{0}^{D_{1}^{-1}(q)} u^{\prime}\left(w_{0}+p q-c q\right) c p f(p) \mathrm{d} p-c \int_{0}^{+\infty} u^{\prime}\left(w_{0}+p q-c q\right) f(p) \mathrm{d} p \\
& <\int_{0}^{D_{1}^{-1}(q)} u^{\prime}\left(w_{0}+p q-c q\right) f(p) \mathrm{d} p \int_{0}^{D_{1}^{-1}(q)} p f(p) \mathrm{d} p-c \int_{0}^{+\infty} u^{\prime}\left(w_{0}+p q-c q\right) f(p) \mathrm{d} p \\
& <\int_{0}^{+\infty} u^{\prime}\left(w_{0}+p q-c q\right) f(p) \mathrm{d} p\left[\int_{0}^{D_{1}^{-1}(q)} p f(p) \mathrm{d} p-c\right] \\
= & \int_{0}^{+\infty} u^{\prime}\left(w_{0}+p q-c q\right) f(p) \mathrm{d} p \frac{\mathrm{d} E \pi}{\mathrm{d} q} .
\end{aligned}
$$


Therefore, $q_{a}<q^{*}$.

Similarly, if $D_{2}(p)$ is not constant at 0 , then $q_{a}<q^{*}$.

\section{Data Availability}

No data were used to support this study.

\section{Conflicts of Interest}

The authors declare that they have no conflicts of interest.

\section{Acknowledgments}

This work was supported by the National Social Science Foundation of China (no. 18BJY108).

\section{References}

[1] H. Golpîra, H. Sadeghi, and S. Bahramara, "Electricity supply chain coordination: Newsvendor model for optimal contract design," Journal of Cleaner Production, vol. 278, Article ID 123368, 2021.

[2] W. Yu, G. Hou, and B. Xin, "Decision-making optimization of risk-seeking retailer managed inventory model in a water supply chain," Discrete Dynamics in Nature and Society, vol. 2021, Article ID 9943753, 18 pages, 2021.

[3] Y. Wei, F. Chen, and H. Wang, "Inventory and production dynamics in a discrete-time vendor-managed inventory supply chain system," Discrete Dynamics in Nature and Society, vol. 2018, Article ID 6091946, 15 pages, 2018.

[4] K. J. Arrow, T. Harris, and J. Marschak, "Optimal inventory policy," Econometrica, vol. 19, no. 3, pp. 250-272, 1951.

[5] C. Koulamas, "A newsvendor problem with revenue sharing and channel coordination," Decision Sciences, vol. 37, no. 1, pp. 91-100, 2006.

[6] M. E. Schweitzer and G. P. Cachon, "Decision bias in the newsvendor problem with a known demand distribution: experimental evidence," Management Science, vol. 46, no. 3, pp. 404-420, 2000.

[7] C. Wang and S. Webster, "The loss-averse newsvendor problem," Omega, vol. 37, no. 1, pp. 93-105, 2009.

[8] Y. Qin, R. Wang, A. J. Vakharia, Y. Chen, and M. M. H. Seref, "The newsvendor problem: review and directions for future research," European Journal of Operational Research, vol. 213, no. 2, pp. 361-374, 2011.

[9] M. Khouja, "The single-period (news-vendor) problem: literature review and suggestions for future research," Omega, vol. 27, no. 5, pp. 537-553, 1999.

[10] N. C. Petruzzi and M. Dada, "Pricing and the newsvendor problem: a review with extensions," Operations Research, vol. 47, no. 2, pp. 183-194, 1999.

[11] L. M. A. Chan, Z. J. M. Shen, D. Simchi-Levi, and J. L. Swann, "Coordination of pricing and inventory decisions: A survey and classification," in Handbook of Quantitative Supply Chain Analysis, pp. 335-392, Springer, Boston, MA, USA, 2004.

[12] C. Canyakmaz, S. Özekici, and F. Karaesmen, "An inventory model where customer demand is dependent on a stochastic price process," International Journal of Production Economics, vol. 212, pp. 139-152, 2019.

[13] J. Olhager, M. Rudberg, and J. Wikner, "Long-term capacity management: Linking the perspectives from manufacturing strategy and sales and operations planning," International Journal of Production Economics, vol. 69, no. 2, pp. 215-225, 2001.
[14] A. Sandmo, "On the theory of the competitive firm under price uncertainty," The American Economic Review, vol. 61, no. 1, pp. 65-73, 1971.

[15] R. S. Pindyck, "The optimal production of an exhaustible resource when price is exogenous and stochastic," in The Impact of Rising Oil Prices on the World Economy, pp. 137148, Palgrave Macmillan, London, UK, 1982.

[16] R. N. Batra and A. Ullah, "Competitive firm and the theory of input demand under price uncertainty," Journal of Political Economy, vol. 82, no. 3, pp. 537-548, 1974.

[17] R. Hartman, "Factor demand with output price uncertainty," The American Economic Review, vol. 66, no. 4, pp. 675-681, 1976.

[18] D. M. Holthausen, "Hedging and the competitive firm under price uncertainty," The American Economic Review, vol. 69, no. 5, pp. 989-995, 1979.

[19] G. Feder, R. E. Just, and A. Schmitz, "Futures markets and the theory of the firm under price uncertainty," The Quarterly Journal of Economics, vol. 94, no. 2, pp. 317-328, 1980.

[20] I. Konstantaras, K. Skouri, and A. G. Lagodimos, "EOQ with independent endogenous supply disruptions," Omega, vol. 83, pp. 96-106, 2019.

[21] L. V. Green, S. Savin, and N. Savva, “"Nursevendor problem”: personnel staffing in the presence of endogenous absenteeism," Management Science, vol. 59, no. 10, pp. 2237-2256, 2013.

[22] T. Ekin, N. G. Polson, and R. Soyer, “Augmented nested sampling for stochastic programs with recourse and endogenous uncertainty," Naval Research Logistics (NRL), vol. 64, no. 8, pp. 613-627, 2017.

[23] T. Ekin, S. Walker, and P. Damien, "Augmented simulation methods for discrete stochastic optimization with recourse," Annals of Operations Research, vol. 153, pp. 1-23, 2020.

[24] S. N. Kirshner and L. Shao, "The overconfident and optimistic price-setting newsvendor," European Journal of Operational Research, vol. 277, no. 1, pp. 166-173, 2019.

[25] S. Mitra and A. K. Chatterjee, "Single-period newsvendor problem under random end-of-season demand," Journal of the Operational Research Society, vol. 69, no. 1, pp. 1-14, 2017.

[26] H. E. Leland, "Theory of the firm facing uncertain demand," The American Economic Review, vol. 62, no. 3, pp. 278-291, 1972.

[27] Y. Wei, S. Xiong, and F. Li, "Ordering bias with two reference profits: Exogenous benchmark and minimum requirement," Transportation Research Part E: Logistics and Transportation Review, vol. 128, pp. 229-250, 2019.

[28] X. T. Wang and J. G. Johnson, "A tri-reference point theory of decision making under risk," Journal of Experimental Psychology: General, vol. 141, no. 4, pp. 743-756, 2012.

[29] X. Long and J. Nasiry, "Prospect theory explains newsvendor behavior: The role of reference points," Management Science, vol. 61, no. 12, pp. 3009-3012, 2015.

[30] M. Wu, T. Bai, and S. X. Zhu, "A loss averse competitive newsvendor problem with anchoring," Omega, vol. 81, pp. 99-111, 2018.

[31] Y. Zhou, C. K. Chan, and K. H. Wong, "A multi-period supply chain network equilibrium model considering retailers' uncertain demands and dynamic loss-averse behaviors," Transportation Research Part E: Logistics and Transportation Review, vol. 118, pp. 51-76, 2018.

[32] C.-Y. Lee, X. Li, and M. Yu, "The loss-averse newsvendor problem with supply options," Naval Research Logistics (NRL), vol. 62, no. 1, pp. 46-59, 2015. 
[33] M. D. Garvey and S. Carnovale, "The rippled newsvendor: a new inventory framework for modeling supply chain risk severity in the presence of risk propagation," International Journal of Production Economics, vol. 228, Article ID 107752, 2020.

[34] B. Vipin and R. K. Amit, "Loss aversion and rationality in the newsvendor problem under recourse option," European Journal of Operational Research, vol. 261, no. 2, pp. 563-571, 2017.

[35] L. Eeckhoudt, C. Gollier, and H. Schlesinger, "The risk-averse (and prudent) newsboy," Management Science, vol. 41, no. 5, pp. 786-794, 1995.

[36] R. Bradley and M. Drechsler, "Types of uncertainty," Erkenntnis, vol. 79, no. 6, pp. 1225-1248, 2014.

[37] R. Bradley and L. K. Bright, "Managing our uncertainty in the crisis,” The Philosopher's Magazine, vol. 90, pp. 32-35, 2020.

[38] H. Zhang, Z. Zhang, L. Zhou, and S. Wu, "Case-based reasoning for hidden property Analysis of judgment debtors," Mathematics, vol. 9, no. 13, p. 1559, 2021.

[39] S. Wu, J. Lin, and Z. Zhang, "New distance measures of hesitant fuzzy linguistic term sets," Physica Scripta, vol. 96, no. 1, Article ID 15002, 2020.

[40] Z. Zhang, X. Zhao, Y. Qin, H. Si, and L. Zhou, "Interval type-2 fuzzy TOPSIS approach with utility theory for subway station operational risk evaluation," Journal of Ambient Intelligence and Humanized Computing, vol. 82, pp. 1-15, 2021.

[41] S. Zhao and Q. Zhu, "A risk-averse marketing strategy and its effect on coordination activities in a remanufacturing supply chain under market fluctuation," Journal of Cleaner Production, vol. 171, pp. 1290-1299, 2018.

[42] K. S. A. Sedzro, S. Kishore, A. J. Lamadrid, and L. F. Zuluaga, "Stochastic risk-sensitive market integration for renewable energy: application to ocean wave power plants," Applied Energy, vol. 229, pp. 474-481, 2018. 